\title{
PROSPECTIVE ROLES OF IL-24 IN THE TUMORIGENESIS AND DEVELOPMENT OF CANCERS
}

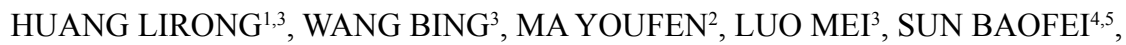 \\ and $\mathrm{LUO} \mathrm{HENG}^{2,3 *}$
}

${ }^{1}$ College of Food and Pharmaceutical Engineering, Guizhou Institute of Technology, Guiyang, China

${ }^{2}$ State Key Laboratory of Functions and Applications of Medicinal Plants, Guizhou Medical University, Guiyang, China

${ }^{3}$ Key Laboratory of Chemistry for Natural Products of Guizhou Province and Chinese Academy of Sciences, Guiyang, China

${ }^{4}$ Key Laboratory of Chemistry for Natural Products of Guizhou Province and Chinese Academy of Sciences, Guiyang, China

${ }^{5}$ The Key Laboratory of Environmental Pollution Monitoring and Disease Control, Ministry of Education, Guizhou Medical University, Guiyang, China

\begin{abstract}
Interleukin-24 (IL-24)/melanoma differentiation-associated gene-7 (mda-7), a novel tumor suppressor/cytokine, exerts tumor-selective inhibition of cells growth, induction of apoptosis, and suppression of angiogenesis in a broad spectrum of cancer cell types without harming the equivalent normal cells. Moreover, the low transcript levels and protein expression of IL-24 have been found to be significantly associated with unfavorable pathological phenotypes in breast cancer tissues. Furthermore, the ectopic expression of IL-24 in cancer cells via transfection with a plasmid comprising IL-24 cDNA or via administration of IL-24 containing recombinant adenovirus (Ad.IL-24) can effectively inhibit the growth and induce apoptosis in a wide array of cancer cells and rodent tumors both in vitro and in vivo. However, overexpression of IL-24 in normal primary cells does not elicit any effect on its growth and viability, indicating that IL-24 can act as a crucial target and therapeutic gene for cancer gene therapy. Mechanistically, the binding of IL-24 cytokine with its receptor pair in different tumor cells activates the JAK-STAT signal transduction pathway, serine/threonine-protein kinase (PKR) pathway, mitochondrial apoptosis signaling pathway, and inhibits CD31/PECAM pathway to inhibit cancer cell growth, induce apoptosis and regulate tumor vascularization. Herein, we reviewed the research progress on biochemical characteristics of IL-24 and its selective role in carcinogenesis, to provide a detailed understanding of the functional mechanism of IL-24. Overall, this study presented IL-24 as a potent antitumor drug target for the development of a more accurate therapeutic strategy and cancer gene therapy.
\end{abstract}

Keywords: IL-24; target therapy; tumorgenesis; tumor suppressor gene

Currently, surgery, chemotherapy, and radiation represent the most effective and extensively used conventional treatment modalities for cancer. Chemotherapy, a drug therapy, involves the use of chemical entities and medications to target the tumor cells and represents a systemic therapy that blocks cell division and DNA replication through genotoxicity $(1,2)$. However, chemotherapy also harms normal cells due to lack of selectivity for tumor cells, leading to diverse systemic toxicity, insufficient drug concentrations in tumors, and adverse effects (3). Besides, the effectiveness of chemotherapy is also limited by the development of drug-resistant tumor cells (4).
To circumvent these concerns, molecular targeted therapy, a newly introduced cancer therapy, by utilizing the drugs (or combination of drugs), antibodies, and other active ingredients exert its anticancer effects by blocking molecules or the tumor tissue microenvironment that drives the cancer phenotype with minimum off-target toxicity to normal cells (5, 6). Moreover, targeted therapeutic drugs more specifically act on cell markers or pathways through diverse mechanisms to inhibit cancer cell proliferation, progression, and metastasis (7). Molecular targeted therapy has the advantages of the targeted release of therapeutic drugs at the site of lesion or selective

* Corresponding author: e-mail: luoheng210901@gmail.com 
localization and specific orientation towards their targets, which substantially reduce the drug dosage, enhance the therapeutic effects and reduce the toxicity to off-target cells (8). Presently, molecular targeted therapeutic research is focused on the selection and development of target molecules that suppress cancer cell proliferation, induce apoptosis or autophagy, promote cell cycle regulation, and provide targeted delivery of toxic substances to cancer cells without affecting normal cells (9-11). Based on the positional relationship between target molecules and cancer cells, targeted therapeutics can act on a specific molecular target within or on the surface (outside) of cancer cells (12). The former indicates the target molecule is located on the cancer cell; the latter suggests the target molecules that are not on the cancer cell but are closely associated with it.

Interleukin-24 (IL-24), also known as melanoma differentiation-associated gene-7 (mda-7), is a novel tumor suppressor/cytokine gene that belongs to the IL-10 cytokine superfamily (13). IL-24 was initially identified and cloned by subtraction hybridization from terminally differentiating human melanoma cells by treatment with a combination of recombinant human fibroblast interferon (IFN-beta) and mezerein (MEZ) to induce terminal differentiation and suppression of tumorigenic abilities (14). In fact, multiple independent studies have demonstrated that IL-24 has been related to many pathological processes involving other human diseases besides cancer, including psoriasis, inflammatory bowel disease, rheumatoid arthritis, tuberculosis, cardiovascular disease, and viral infection (15). In early studies, MDA-7 was recognized to exhibit antitumor effects against a variety of cancer types, while sparing the normal cells unharmed both in vitro and in vivo (16). In subsequent years, it was revealed that IL-24/MDA-7 was explicitly expressed in tissues related to the immune system, including the thymus, spleen, macrophages, and peripheral blood leukocytes, normal melanocytes, and keratinocytes (17-19). Subsequent sequence analysis of MDA-7 revealed a stretch of 21 amino acids, corresponding to an IL-10 signature sequence. Considering the presence of an IL-10 signature motif, chromosomal localization, and expression profile, MDA-7 was renamed IL-24 in 2002 (20). Furthermore, studies have shown that the IL-24 protein expression was significantly reduced in malignant breast tissue and low transcript levels were markedly associated with unfavorable pathological characteristics and adverse clinical outcomes (21). Under anchorage-independent culture conditions, the exogenous expression of IL-24 inhibited the growth of cells in monolayer culture and soft agar, reduced their ability to migrate and invade in vitro, and the development of tumors in nude mice in vivo; however, it exhibited no apparent effects on normal cells tissues $(22,23)$. Extensive research indicated that IL-24 as a tumor suppressor gene shows potent anticancer effects affecting a broad spectrum of cancers, suggesting that IL-24 could be used as an active therapeutic target for cancer therapy. Moreover, IL-24 has also been shown to be efficacious in Phase I/II of clinical trials in multiple advanced cancers $(15,24)$. Several recent studies have confirmed that IL-24 inhibits carcinogenesis and development by inducing cancer cell death through apoptosis and toxic autophagy and by suppressing cancer cell invasion and migration via different molecular mechanisms in vitro and in preclinical animal models in vivo $(15$, $25,26)$. Considering these pieces of evidence, this review aims to summarize the role of IL-24 in carcinogenesis for providing a systematic understanding to establish and utilize IL-24 as a novel therapeutic target or cancer-gene therapy.

\section{The biochemical characteristics and functions of IL-24}

The human MDA-7/IL-24 gene comprises of seven exons and six introns that are located on chromosome 1q32-33, within the cluster containing the IL-19 and IL-20 cytokine genes. The mda-7/IL-24 mRNA is 1718 base pairs long and encodes a protein of 206 amino acids with a predicted size of approximately $24 \mathrm{kDa}$ (27). As a secretory cytokine, MDA-7/ IL-24 has a 49-amino acid N-terminal hydrophobic putative signal peptide (28). Further sequence alignment of amino acids indicates that IL-24 shares a 20$30 \%$ amino acid homology to other members (IL-10, IL-20, and IL-22) of the IL-20 family of cytokines (29). Based on amino acid homology, chromosome localization, and cytokine-like properties, IL-24 is a member of the IL-10 family. IL-24 is characterized as a multi-functional cytokine in different tissues based on biological functions and biochemical characteristics (Fig. 1) (30). There is a potent hydrophobic signal peptide comprised of 49 amino acids at the N-terminus of the encoded IL-24 protein, and its conserved signal peptidase cleavage site is located between amino acids 49 and 50 (31). Analysis of the primary structure of IL-24 protein identified three putative $\mathrm{N}$-glycosylation sites at amino acid 85,99 , and 126; three casein kinase II consensus phosphorylation sites at amino acid positions 101, 111 and 161; protein kinase $\mathrm{C}$ phosphorylation sites at amino acid positions 88, 133 and 161; and IL-24 contains a conserved IL-10 signature motif amino acid between 101 and 121. IL-24 protein is an $\alpha$ 
helix secretory protein, and its secondary structure contains six $\alpha$ helices $(32,33)$, belonging to the reticulated helix structure $(34,35)$. A previous study demonstrated significant inhibition of breast cancer tumor development following injection with an adenovirus carrying mda-7/IL-24 directly into the main mammary ducts of rats induced with methyl nitrosourea (MNU) to develop breast cancer, suggesting that IL-24 can be used as a specific target for breast cancer therapy. Furthermore, the autocrine feedback loop of IL-24 protein induces apoptosis in some cancer cells through different specific target molecules (36), such as chronic lymphocytic leukemia B cells through dephosphorylation of STAT3 (37), of ovarian cancer cells mainly through the fas/fasL pathway (38), of malignant cerebral glioma through the caspase-, cathepsin- and PERK dependent pathway (39), of melanoma cells through class-I interferonregulated signaling pathway (40), and of malignant renal carcinoma cells through ceramide/CD95/PERK dependent mechanism (41).

The initial evidence of IL-24 as a putative therapeutic target for cancer was derived from the study by Madireddi and Fisher, which indicated that IL-24 mRNA was markedly upregulated in early melanoma cells and normal melanocytes; however, mRNA or protein expression of IL-24 gradually reduced as the increased degree of malignancy, and it remains undetected in metastatic melanoma cells or tissues (42). Moreover, IL-24 is normally expressed in tissues of the immune system including spleen, thymus, and peripheral blood leukocytes, and in some special types of cells, such as normal melanocytes, ticks, early melanoma cells, smooth muscle cells, skin fibroblasts, skin wound edges, basal fibroblasts, and keratinocytes $(43,44)$. Endogenous IL-24 protein expression was lost in more than 50 tumor cell lines (44), whereas, exogenous induction of IL-24 by phytohemagglutinin (PHA), lipopolysaccharide (LPS), or transfection with an adenoviral (Ad) expression system expressing exogenous IL-24 (Ad. IL-24) can induce the endogenous expression of IL-24 to specifically inhibit the proliferation and metastasis of cancer cells. An increasing number of studies have confirmed that overexpression of IL-24 through adenovirus encoding IL-24 suppressed the proliferation of a variety of cancer cells (Table 1), including melanoma, renal carcinoma, fibrotic sarcoma, breast cancer, and osteosarcoma (45), cervical cancer (46), lung cancer (47), colon cancer, nasopharyngeal cancer (48), esophageal cancer (49), ovarian cancer (50), prostate cancer (51), pancreas cancer (52), leukemia (53), and colorectal cancer $(54,55)$. However, its overexpression did not affect the function and growth of the normal cells, such as fibroblasts, astrocytes, epithelial cells, melanocytes, or endothelial-derived cells $(29,56,57)$. In fact, IL-24 functions as a cytokine at normal physiological levels in normal cells and plays a role in immune regulation, autoimmune disease, wound healing, and defense against bacterial infections (58); when IL-24 is overexpressed in cancer cells, IL-24 can selectively inhibit the differentiation of various tumor cells by causing a G2/M cell cycle arrest and then inducing apoptosis (59). Thus, IL-24 initially demonstrated to be associated with melanoma cell differentiation has now been established as a multi-functional cytokine affecting a wide array of cancers $(60,61)$, which can induce

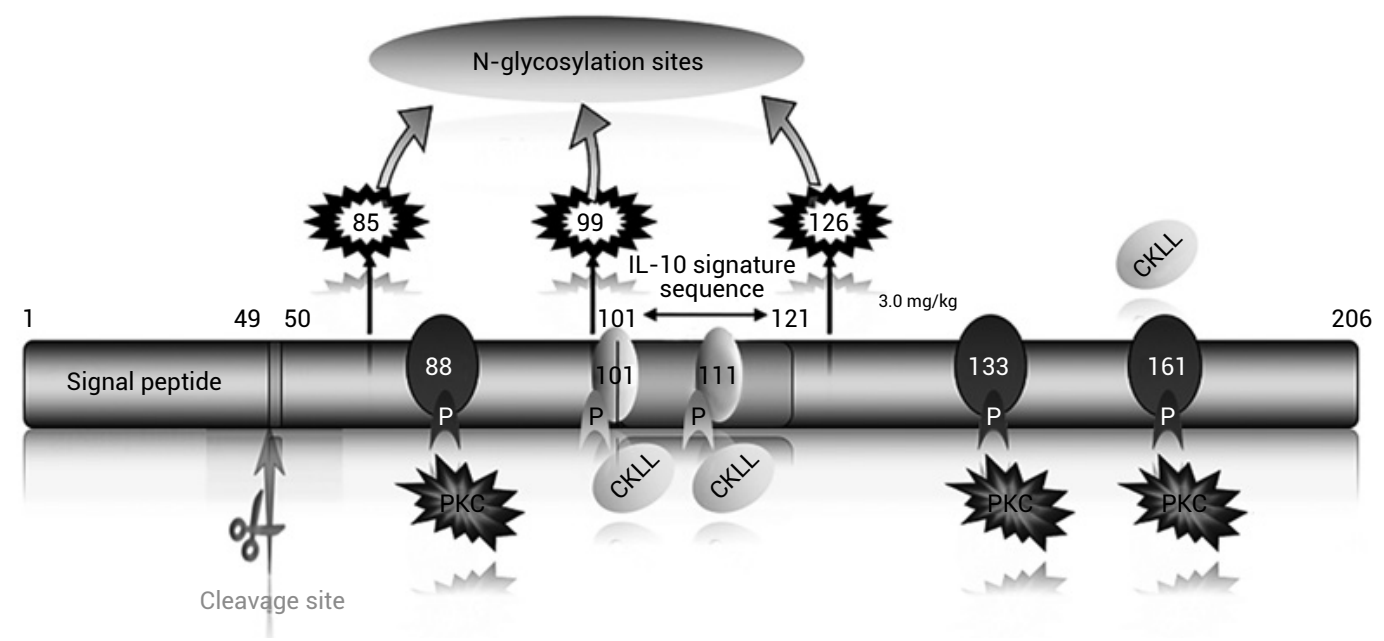

Figure 1. Schematic representation of IL-24 protein with predicted and established domains and protein modification sites illustrated. IL-24 contains an IL-10 signature sequence between amino acids 101 and 121 . The IL-24 signal peptide is cleaved to allow the secretion of IL-24 protein. IL-24 is glycosylated at three sites at amino acids 85, 99, and 126. Protein kinase C consensus phosphorylation sites are present at amino acids 88, 133, and 161, while Casein kinase II (CKII) consensus phosphorylation sites are present at amino acids 101, 111 , and 161. Numbers indicate amino acids. 
Table 1. A summary of IL-24-related tumors, mechanisms, cell types, and effects.

\begin{tabular}{|c|c|c|c|c|}
\hline IL-24 & Tumor type & Cell type & Related mechanisms & Effect on tumor \\
\hline Ad-IL-24 & Glioma & U251 & $\begin{array}{l}\text { Up-regulation of bax/bcl-2, ICE, } \\
\text { c-myc, p53 and down-regulation of } \\
\text { HIF- } 1 \alpha\end{array}$ & $\begin{array}{l}\text { Induced apoptosis of tumor } \\
\text { cells }\end{array}$ \\
\hline Ad-IL-24 & Breast cancer & CaSki & $\begin{array}{l}\text { Increased cleaved caspase-3 protein } \\
\text { expression }\end{array}$ & $\begin{array}{l}\text { Inhibited tumor formation } \\
\text { and promoted tumor cell } \\
\text { apoptosis }\end{array}$ \\
\hline IL-24 & $\begin{array}{c}\text { B-cell } \\
\text { lymphoma }\end{array}$ & Raji and Daudi & $\begin{array}{c}\text { The expression levels of MDR1, } \\
\text { MRP1,BMI1, total ERK1/2, } \\
\text { and p-ERK1/2 decreased while } \\
\text { the amount of intracellular } \\
\text { Rhodamine-123 accumulated } \\
\text { increased }\end{array}$ & $\begin{array}{l}\text { Enhanced chemosensitivity } \\
\text { of B-cell lymphomas }\end{array}$ \\
\hline IL-24 & $\begin{array}{l}\text { Esophageal } \\
\text { tumor }\end{array}$ & $\begin{array}{l}\text { Eca-109 and } \\
\text { TE-1 }\end{array}$ & $\begin{array}{l}\text { Eca-109 and TE-1 cells are arrested in } \\
\text { G1 G0 phase }\end{array}$ & $\begin{array}{l}\text { Inhibited proliferation of } \\
\text { esophageal cancer cells }\end{array}$ \\
\hline Ad-IL-24 & $\begin{array}{l}\text { Oral squamous } \\
\text { cell carcinoma }\end{array}$ & $\mathrm{KB}$ and $\mathrm{KBV}$ & $\begin{array}{l}\text { Inhibits cell growth and promotes } \\
\text { apoptosis }\end{array}$ & $\begin{array}{l}\text { Cytotoxicity and induced } \\
\text { apoptosis }\end{array}$ \\
\hline Ad-IL-24 & Lung cancer & SPC-A1 & $\begin{array}{l}\text { Upregulates bax, Caspase-3, and } \\
\text { downregulates expression of bcl- } \\
2 \text { and survivin }\end{array}$ & $\begin{array}{l}\text { Induced tumor cell } \\
\text { apoptosis }\end{array}$ \\
\hline IL-24 & Cervical cancer & Sina & $\begin{array}{l}\text { Down-regulate VEGF-D and } \\
\text { upregulate Caveolin-1 expression }\end{array}$ & $\begin{array}{c}\text { Inhibited the ability of } \\
\text { lymphatic metastasis of } \\
\text { Siha tumor cell lymphatic } \\
\text { metastasis }\end{array}$ \\
\hline IL-24 & Liver cancer & $\begin{array}{l}\text { HepG2,Hep3B } \\
\text { MHCC97L }\end{array}$ & Stop liver cancer cells in $\mathrm{G} 2 / \mathrm{M}$ phase & $\begin{array}{l}\text { Promoted cell proliferation } \\
\text { arrest and induced } \\
\text { apoptosis }\end{array}$ \\
\hline Ad-IL-24 & Stomach cancer & SGC-7901 & $\begin{array}{l}\text { Upregulate the expression of Bax, } \\
\text { caspase-3, and p53 and downregulate } \\
\text { the expression of BCL-2 in SGC- } \\
7901 \text { gastric cancer cells }\end{array}$ & $\begin{array}{l}\text { Inhibited growth and } \\
\text { induced apoptosis in SGC- } \\
7901 \text { Human gastric cancer }\end{array}$ \\
\hline $\begin{array}{c}\text { CNH } \\
\text { K600-IL-24 }\end{array}$ & Breast cancer & MDA-MB-231 & $\begin{array}{l}\text { IL-24 protein expression is } \\
\text { upregulated, and apoptosis is } \\
\text { significantly increased }\end{array}$ & Kill tumor cells \\
\hline ZD55-IL-24 & Melanoma & MV3 & $\begin{array}{l}\text { upregulated the expression of Bax and } \\
\text { E1A while decreased expression of } \\
\text { BCL-2 and Caspase-3 activation was } \\
\text { more pronounced }\end{array}$ & $\begin{array}{l}\text { Synergistic killer } \\
\text { melanoma cells }\end{array}$ \\
\hline $\begin{array}{l}\text { Ad-ING4- } \\
\text { IL-24 }\end{array}$ & Osteosarcoma & MG-63 & $\begin{array}{l}\text { Upregulate the expression of genes } \\
\text { such as Bax, P21 and Caspase- } 3 \text {, and } \\
\text { down-regulate the expression of BCL- } \\
2 \text { and CD34 }\end{array}$ & $\begin{array}{l}\text { Inhibited cancer cell } \\
\text { proliferation }\end{array}$ \\
\hline IL-24 & Prostate cancer & PC-3 & $\begin{array}{l}\text { Upregulate p53, Bax, Caspase- } 3 \text { gene } \\
\text { expression and down-regulate Bcl- } \\
2 \text { gene expression }\end{array}$ & Induced apoptosis \\
\hline Ad-IL-24 & $\begin{array}{l}\text { Nasopharyngeal } \\
\text { carcinoma }\end{array}$ & CNE-2Z & $\begin{array}{l}\text { IL-24 inhibits CNE-2Z cell } \\
\text { proliferation and induces apoptosis in } \\
\text { a time and dose-dependent manner }\end{array}$ & $\begin{array}{l}\text { Inhibited cell growth and } \\
\text { induced apoptosis }\end{array}$ \\
\hline IL-24 & Ovarian cancer & SKOV3 & $\begin{array}{l}\text { Upregulation of IL-24 mRNA } \\
\text { expression }\end{array}$ & $\begin{array}{l}\text { Inhibited migration and } \\
\text { invasion of ovarian cancer } \\
\text { cells }\end{array}$ \\
\hline IL-24 & Bladder cancer & Organization & $\begin{array}{c}\text { The expression rate of IL- } 24 \text { mRNA } \\
\text { in invasive bladder cancer is lower } \\
\text { than that of superficial carcinoma and } \\
\text { related to tumor grade }\end{array}$ & $\begin{array}{l}\text { Inhibited bladder cancer } \\
\text { growth, metastasis, and } \\
\text { induced apoptosis }\end{array}$ \\
\hline
\end{tabular}


Table 1. A summary of IL-24-related tumors, mechanisms, cell types, and effects (cont.).

\begin{tabular}{|c|c|c|c|c|}
\hline IL-24 & Tumor type & Cell type & Related mechanisms & Effect on tumor \\
\hline IL-24 & $\begin{array}{c}\text { Small intestine } \\
\text { cancer }\end{array}$ & HIC & $\begin{array}{c}\text { IL-24 fusion protein inhibits } \\
\text { the growth of HIC cells in } \\
\text { a concentration-dependent manner }\end{array}$ & $\begin{array}{c}\text { Inhibited cancer cell } \\
\text { growth }\end{array}$ \\
\hline IL-24 & Renal carcinoma & Organization & $\begin{array}{c}\text { Expression of IL-24 mRNA decreases } \\
\text { gradually with the extent of tumor } \\
\text { progression }\end{array}$ & $\begin{array}{c}\text { As an indicator of kidney } \\
\text { cancer biology }\end{array}$ \\
\hline IL-24 & Leukemia & $\begin{array}{c}\text { Organization } \\
\text { BW5147 cell } \\
\text { lines }\end{array}$ & $\begin{array}{c}\text { Engaged into the cell cycle through } \\
\text { dephosphorylation of STAT3 and } \\
\text { stabilization of p53 expression }\end{array}$ & $\begin{array}{c}\text { Induced apoptosis of B } \\
\text { cells }\end{array}$ \\
\hline VG9-IL-24 & $\begin{array}{c}\text { Colorectal } \\
\text { cancer }\end{array}$ & $\begin{array}{c}\text { HCT16, HCT- } \\
8, \text { BSC-40 }\end{array}$ & $\begin{array}{c}\text { Induced increased number of } \\
\text { apoptotic cells and blocked colorectal } \\
\text { cancer cells in the G2/M phase of the } \\
\text { cell cycle }\end{array}$ & $\begin{array}{c}\text { Inhibited cancer cell } \\
\text { growth }\end{array}$ \\
\hline
\end{tabular}

apoptosis or inhibit proliferation in different cancer cells through diverse mechanisms. Above all, IL-24 plays an essential role in the regulation of cell proliferation, differentiation, and tumorigenesis, and development of various cancers, suggesting IL-24 can serve as a potential putative molecular target and therapeutic gene in cancers.

\section{The anticancer mechanism of IL-24}

Several studies have confirmed that IL-24 possesses a wide spectrum of anticancer activities by a different molecular mechanism in a variety of cancerous tissues $(61,62)$. IL-24 presents cancer-specific activity (cell death, apoptosis, or autophagy) by promoting ER stress and modulating multiple signal transduction pathways regulating cancer cell growth, invasion, metastasis, survival, and angiogenesis (15, $25,55)$. For inhibiting cancer cell growth, inducing apoptosis, and regulating angiogenesis, the canonical mechanism by which IL-24 cytokine is proposed to mediate its activity is by binding to cell surface receptors and activating the Janus-activated kinase/ signal transducers and activators of transcription (JAK-STAT) signaling $(56,63)$, serine/threonineprotein kinase (PKR) $(64,65)$, mitochondrial apoptosis signaling $(66,67)$, and CD31/PECAM pathways $(46,68)$ (Fig. 2). Thus far, IL-24 has been recognized to utilize two heterodimers receptors, including

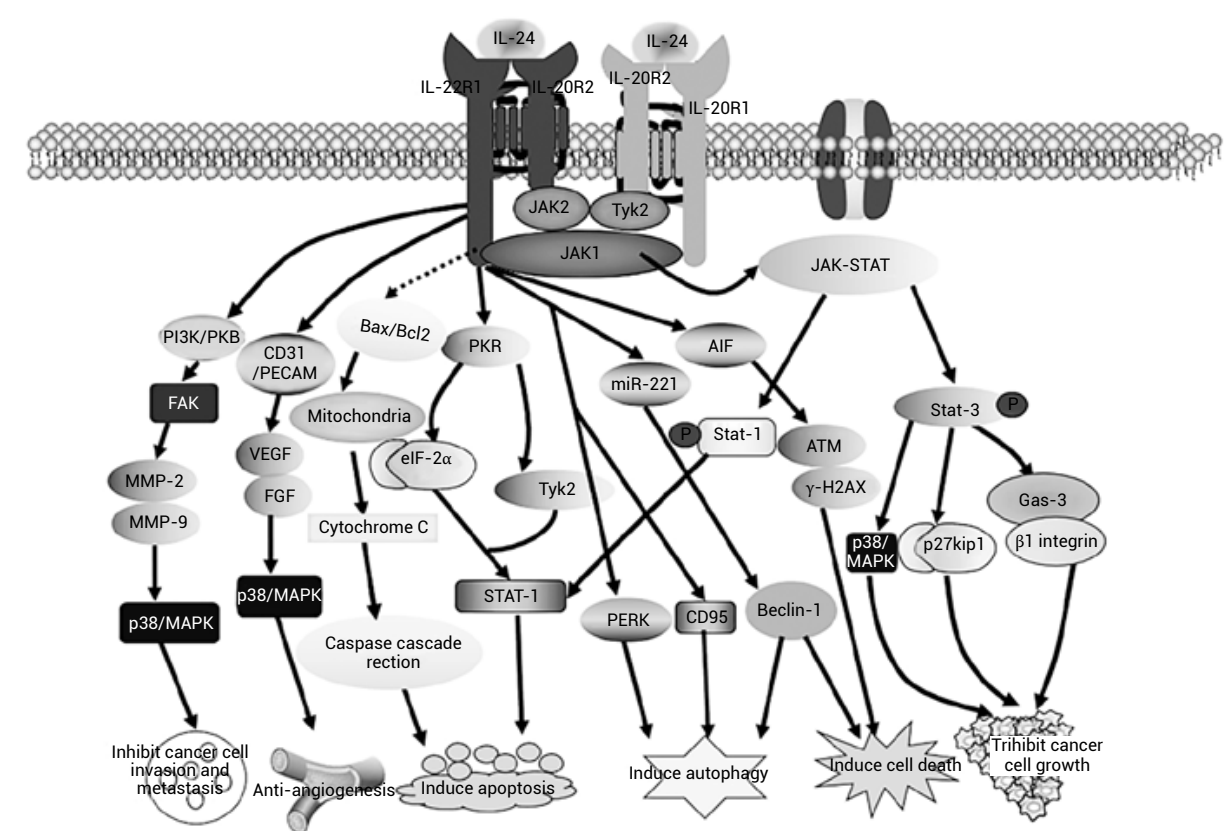

Figure 2. Illustration of IL-24 cytokine canonical carcinogenic signaling pathways inducing cancer cell growth, invasion, apoptosis, anti-angiogenesis, and autophagy by binding to cell surface receptors, including Janus-activated kinase/signal transducers and activators of transcription (JAK-STAT) signaling, serine/threonine-protein kinase (PKR), mitochondrial apoptosis signaling, and CD31/PECAM pathways. 
IL-20R1/IL-20R2 and IL-22R1/IL-20R2, to activate downstream signaling by ligand affinity-tagged assays (69). Furthermore, using a ligand-dependent STAT for receptor activation, Dumoutier and colleagues also independently identified the same receptors (70). Similar to the IL-10 family, IL-24 functions through its receptors consisting of R1 and R2 subunits. R1 subunit and ligand bind with higher affinity; R1 has a longer cytoplasmic tail, which binds to JAK1 casein kinase to determine the specificity of the signaling pathway; the R2 subunit does not bind to ligands and has a shorter cytoplasmic tail which binds to JAK2 or Tyk2. The only function of R2 is to recruit another casein kinase to the receptor to initiate signal transduction (70). Classically, signal transduction of IL-24 activates the JAK-STAT and PKR signaling pathway by binding to the receptor pairs and inducing phosphorylation and nuclear translocation of downstream signaling molecules. However, the JAK-STAT signaling pathway cannot be activated if only one of the receptors is bound; it could be activated when both of the receptors bind to IL-24.

\section{IL-24 inhibits cancer cell proliferation through the regulation of the JAK-STAT signaling pathway}

IL-24 protein binds with its receptors complexes activates JAK and induces phosphorylation of Stat1 and Stat-3 of JAK-STAT signaling pathway to inhibit cancer cell growth (71). However, the target genes and biological effects of IL-24 through STAT signal transduction pathways remain to be completely elucidated. Accumulating studies have indicated that exogenous expression of IL-24 induces inhibition of tumor cells; however, it does not elicit any harmful effects on normal cells, which may be attributed to the different types of receptors that bind to IL-24 and signaling pathways in tumor cells and normal cells. IL-24 activates the JAK/STAT pathway by binding to IL-20R1/L-20R2 and IL-22R1/L20R2 receptors on the cell membrane and causing phosphorylation of various signaling proteins and transcription factors, including Stat-3 and Stat-1. Furthermore, Phosphorylated Stat-3 can homodimerize, or heterodimerize with STAT1, and subsequently undergo nuclear translocation to regulate the expression of the downstream target genes involved in the suppression of cancer cell growth and induction of cancer cell apoptosis $(63,72,73)$. Alternatively, IL-24 can also inhibit cancer cell growth by regulating the transcription of $\mathrm{p} 27 \mathrm{kip} 1$ in the cytoplasm that is activated by phosphorylated Stat-3 (74). Moreover, IL-24-induced phosphorylated Stat-3 can directly regulate the transcription of its target gene growth arrest-specific gene-3 (Gas-3) involved in the inhibition of breast cancer cell growth. The upregulation of Gas3 by IL-24 is dependent on STAT3 expression and phosphorylation. A mutant Gas-3 that cannot bind to $\beta 1$ integrin cannot inhibit fibronectin-mediated adhesion and cell growth in adherent and suspension cultures, suggesting that Gas-3 acts through binding and regulating $\beta 1$ integrin (75). These results indicated that inhibition of IL-24 expression on breast cancer growth was achieved at least in part by upregulating the expression of Gas-3 and disrupting the function of $\beta 1$ integrin. It has also been found that the appearance of IL-24 receptor IL-20R1 is associated with the expression of Gas-3 in human breast cancer, and the high expression of IL-20R1 in HER2+ breast cancer patients could also significantly reduce the incidence of tumor metastasis (76). Interestingly, IL-24-induced phosphorylation of Stat-1 was associated with the regulation of the PKR pathway in IL-24-caused cell apoptosis (77). Together, these studies suggested that IL-24 may be a multi-functional protein that can function through different molecular mechanisms.

In fact, Li's group also found no expression of IL-24 in normal mammary gland cells of Cop and WF rats, and further demonstrated that if the expression of IL-24 is induced in the precancerous lesions of Cop rats, it will not develop into a tumor, particularly for breast cancer. However, in some cells (such as cancer cells), there may be other IL-24 receptors that have not yet been revealed. Possibly, binding of IL-24 with an unknown receptor may also activate the JAK/STAT pathway or an unknown pathway to induce selective apoptosis in mutant cells, which is absent in normal cells, conceivably, exogenous expression of IL-24 in abnormal cells may induce direct apoptosis via other unknown pathways.

\section{IL-24 induces apoptosis through the regulation of the PKR signaling pathway}

Apoptosis plays a critical role in inducing sensitivity to cancer therapeutics. Cancer cells evade the mechanism of cell death; thus, understanding the mechanism by which cancer cells escape apoptotic pathways remains crucial for the development of new therapeutics against cancer. Overexpression of IL-24 could induce apoptosis in different cancer cells without causing a harmful effect on normal cells. Exogenous expression of IL-24 protein has been shown to exhibit specific anticancer effects by regulating multiple signaling cascades of the PKR pathway in various cancer cells. A study on a mouse model of breast cancer demonstrated that IL-24 protein exhibited anticancer effects by activating the PKR pathway in cancer cells and selectively inducing apoptosis in 
breast cancer cells without affecting the physiology of normal cells activity (78). Further genomics and molecular biology experiments confirmed that the apoptosis processes induced by IL-24 protein do not involve in the regulation of tumor-associated gene P53 in breast cancer cells; however, the exogenous expression of IL-24 gene induced into P53-deficient mouse breast cancer cells can significantly inhibit the growth of breast cancer cells in the mouse. In addition, related studies using eukaryotic expression vector of IL-24 into non-small cell lung cancer cells have shown that the exogenous expression of IL-24 gene can activate and upregulate the expression of PKR to phosphorylate the downstream target genes of PKR, including eukaryotic translation initiation factor $2 \alpha$ (elF-2 $\alpha$ ) and tyrosine kinase 2 (Tyk2), which further activate STAT-1 and P38/MAPK signaling pathways in lung cancer cells (48). Therefore, the PKR signaling pathway provides a key molecular mechanism implication of IL-24 as a new therapeutic target for cancer.

\section{IL-24 induces apoptosis through the regulation of the mitochondrial apoptosis signaling pathway}

The molecular mechanism underlying the anticancer effect of IL-24 includes inhibition of protooncogenes and activation of tumor suppressor genes and pro-apoptotic genes of the mitochondrial apoptosis signaling pathway. Apoptosis is strictly regulated by anti-apoptotic and pro-apoptotic proteins of the BCL2 family. The anti-apoptotic proteins include BCL-2, BCL-xL, MCL-1, BCL-w, and Ad-E1B, while proapoptotic proteins include Bax, Bad, Bak, and Bcl-X. Using Ad-IL24 infection, studies have suggested that IL-24 induced apoptosis exclusively in breast cancer cells irrespective of their p53 status (p53-wild type, p53 mutant, or p53-null breast cancer cell); besides, these studies also demonstrated that Ad.IL-24 also upregulated the expression of the pro-apoptotic factor Bax and increased the ratio of Bax to the antiapoptotic factor Bcl-2. Thus, increased expression of Bax and decreased expression of Bcl-2 protein represented the crucial regulatory components in the regulation of the mitochondrial apoptosis signaling pathway in Ad.IL-24-induced apoptosis $(15,26)$. In addition, by upregulating the expression of pro-apoptotic proteins Bax and Bak and down-regulating the expression of anti-apoptotic protein Bcl-2 and BclXL, IL-24 promoted a shift from survival to programmed cell death in B-cell lymphoma transfected with an IL-24 expression vector (79). However, prostate cancer cells with lower Bax expression were also found to be susceptible to apoptosis by IL-24 (80). Alternatively, IL-24 overexpression induces cancer cell-specific oxidative stress through the generation of ROS followed by induction of mitochondrial dysfunction and loss of mitochondrial membrane potential specifically in cancer cells (81). Besides, IL-24 induces the pro-apoptotic effects, including, but not limited, to modulating Bcl family and ROS formation produced during mitochondrial damage. IL-24 induces apoptosis, including oxidative stress uniquely in tumor cells of different tissue origin but does not harm normal cells (82). Using immunohistochemistry assay, IL-24 protein was found to induce the expression of a variety of pro-apoptotic factors in the apoptosis-induced lung cancer cells (83). Further related studies have indicated that Ad-IL24 can down-regulate the expression of anti-apoptotic protein $\mathrm{Bcl}-2$ (54) and induce the release of cytochrome c, thereby facilitating the activation of caspase-9, caspase-3, and PARP-1 to induce apoptosis in various cancers cell. However, the molecular mechanism underlying the interaction between the mitochondrial apoptosis signaling pathway and the receptor binding IL-24 remains elusive. Nevertheless, the regulation of the mitochondrial apoptosis signaling pathway by IL-24 exerts an important role in IL-24-induced apoptosis, highlighting the potential of IL-24 as the new strategy for selective therapy for cancers.

\section{IL-24 induces cell death through the regulation of $\mathrm{AIF} / \mathrm{ATM} / \mathrm{\gamma}-\mathrm{H} 2 \mathrm{AX}$ pathway and miR-221-beclin-1 axis}

The study has revealed that IL-24 induces specific cell death (caspase-independent apoptosis) in neuroblastoma through a novel mechanism involving the modulation of AIF, ATM, and $\gamma-\mathrm{H} 2 \mathrm{AX}$ (84). This previously unrecognized pathway associated with the regulation of AIF expression and translocation into the nucleus of neuroblastoma cells that is dependent on the induction of ATM leading to the nuclear translocation and phosphorylation of $\gamma-\mathrm{H} 2 \mathrm{AX}$ into the nucleus (84), which provides a new clarification on the applications for potential therapy of the cancer cells using the near-ubiquitous cancer-suppressing gene. Other studies have also confirmed that either ectopic expression of IL-24 promotes the downregulation of miR-221 and upregulation of p27 and PUMA for culminating in cell death of a series of cancer cells (85). In fact, the reactive oxygen species induction was associated with IL-24-induced cancer cell death that was recovered by overexpression of miR-221 (85). Besides, the cloned miR-221 overexpressing human breast cancer cells were more aggressive and resistant to IL-24-mediated cell death than that of parental cells using an animal model study. Furthermore, beclin-1 is a new transcriptional target of miR-221. 
miR-221 and the beclin-1 can form an axis in many cancer cells $(15,17,26)$. which indicated that IL-24 regulates a specific subset of miRNAs, including cancer-associated miR-221. The study suggested that IL-24 mediates cancer cell-specific death via regulation of miR-221 and the beclin-1 axis regulation of miR-221 and the beclin-1 axis in various types of cancers (85) This is the first finding that IL-24 directly mediates microRNA expression in cancer cells and highlights the important role and application of the IL-24-miR-221-beclin-1 loop in mediating cancer cell-specific death by a cancer-suppressing gene.

\section{IL-24 induces autophagy through the regulation of PERK, beclin-1, and CD95}

IL-24 induces cancer cell autophagy, which was regulated by PERK, beclin-1, and CD95 (15, 86-88). The studies have demonstrated IL-24 induces autophagy to regulate in different cancer cells by different mechanisms, and its role was also different. In glioblastoma (GBM) and transformed fibroblasts, IL-24-mediated autophagy was regulated by activation and phosphorylation of PERK that results from cytokine-induced ER stress. Therefore, prolonged PERK activity can result in cell death (86). Loss of PERK expression in the cells enhanced the resistance to IL-24-induced autophagy and cell death (89). Likewise, IL-24 induced autophagy and cell death were disturbed by overexpression of BiP/GRP78 via inhibiting PERK activation (90). Conversely, activation of PERK triggered the vacuolization of LC3 protein and lead to an upregulation of autophagy markers like ATG5 and beclin1 (90). A very important finding is that the inhibition of autophagy by suppression of key mediators such as beclin1 and ATG5, and by treating with a chemical inhibitor, 3-methyl adenine, dramatically attenuated the sensitivity of IL-24 in the cancer cells through inhibiting PERK activation (90). However, in prostate cancer cells, autophagy plays a different role in IL-24 treatment. Unlike GBM cells, blocking autophagy in prostate cancer cells by using 3-methyl adenine or by suppressing the expression of beclin1 enhanced IL-24 cytotoxicity via increasing PERK activation and activation of pro-apoptotic molecules like Bax and Bak (87). Subsequent studies in renal carcinoma have found a direct correlation that the block of IL-24-induced autophagy was caused by suppression of ATG5 and/or beclin1 expression (88).

IL-24 regulates miR-221 that is an oncogenic microRNA in the process of inducing cell death. The same study has also found that miR-221/beclin-1 feedback loop is involved in the regulation of IL-24-induced autophagy (85). Downregulation of miR-221 by IL-24 turn induces beclin-1, leading to autophagy, because of beclin-1 as a new transcriptional target of miR-221, which indicated that the small molecule microRNA that can control autophagy may provide application benefit in certain cancers. In renal and ovarian cancers, an important regulatory molecule, CD95, plays a crucial role in the induction of autophagy caused by IL-24 (86). Treatment of renal carcinoma cells with IL-24 enhanced ER stress response via CD95 signaling eliciting autophagy and cell death (88). The reports have shown that drug-induced activation of CD95 resulted in a protective response of autophagy that promoted the growth in melanoma, hepatoma, renal, and pancreatic cancer cells (86). Thus, IL-24 induces autophagy in various cell types, but the precise roles of autophagy in response to IL-24 vary greatly according to the cancer cell types. The differential response induced by IL-24 in a wide variety of cancer cells could be attributed to the inherent complexities in cancer cells.

\section{IL-24 regulates the development of cancer through suppression of tumor angiogenesis and invasion and metastasis}

Tumor vascularization is crucial for maintaining tumor cell proliferation and providing a primary escape route for tumor metastasis. Exogenous expression of IL-24 can down-regulate CD31/PECAM gene expression in tumor-bearing nude mice, indicating that IL-24 has significant anti-angiogenic effects as CD31 can indirectly interact with the alteration of tumors microvascular density. Following overexpression of exogenous IL-24 in human umbilical vein endothelial cells, its vascular-like structure was inhibited, confirming the hypothesis that IL-24 inhibits tumor angiogenesis. In this context, Ramesh et al. found that IL-24 can inhibit endothelial cell differentiation and growth induced by vascular endothelial growth factor (VEGF) and FGF in vitro. Yet another study demonstrated that IL-24 could inhibit neovascularization in nude mice injected with non-small cell lung cancer (p53 wild-type) and H1299 (p53 deficient) lung cancer cells (52). Inhibition of tumor angiogenesis by IL-24 may be related to IL-22R receptor on the cell membrane surface, and related studies have also revealed that IL-24 inhibits tumor angiogenesis and may also relate to the PI3K pathway (79). At present, the IL-24 gene is the first gene that has been found to both inhibit tumor cell growth and differentiation and angiogenesis, and at the same time, stimulate the expression of related cytokines and induce apoptosis in cancer cells. Inhibitory genes, such as P53, P10, and Rb, are being used in gene therapy in clinical trials; however, they exhibited no antitumor 
activity upon activation of their expression through exogenous induction. Therefore, understanding the regulation of IL-24 gene expression has theoretical and clinical significance.

IL-24 also plays an important role in inhibiting tumor cell invasion and metastasis. Invasion and metastasis are important processes in the development of tumors. Once tumor cells have invaded and metastasized to distant parts of the body, the treatment options and survival rates will face great challenges $(15,26)$. IL-24 was shown to inhibit the invasion and migration of several cancer cells. IL-24 can inhibit the migration and invasion of human nonsmall cell lung carcinoma cells (H1299 and A549) in vitro by downregulating the expression of PI3K/ PKB, FAK, MMP-2, and MMP-9, which has been confirmed in an in vivo experimental study using lung metastasis model $(57,72)$. Exogenous expression of IL-24 significantly reduced in vitro migration and invasion of human cervical cancer cells (CaSki) due to down-regulation of MMP-2 and upregulation of p38 MAPK (86). Similarly, overexpression of IL-24 in human hepatocellular carcinoma cells (HepG2 and Bel-7402) significantly inhibited cell adhesion and invasion, induced G2/M cell cycle arrest in vitro by regulating the expression of metastasis-related genes including CD44, ICAM-1, MMP-2, MMP-9, Cyclin B1, Twist, Survivin, TGF- $\beta$ and pAkt and downregulating NF- $\mathrm{B}$ transcriptional activity $(91,92)$, but not in normal hepatocytes (L02) (14). By constructing a non-secreted expression vector of IL-24 (lacking a secreted signal peptide), the study determined whether IL-24-mediated invasion and metastasis inhibition is achieved by binding to its homologous receptor or in a manner independent of receptor signal transduction. The results showed that the secreted and non-secreted IL-24 vectors infected with prostate cancer cells (C8161) had similar inhibitory effects on stromal cell invasion and metastasis (32), indicating that IL-24 could inhibit invasion both through receptor-mediated and receptor-independent pathways.

\section{Targeting IL-24 in cancer treatment}

As a cancer-specific therapeutic cytokine, IL-24 represents a novel target strategy for developing new anticancer drugs and genes therapy in a wide array of cancers. However, a further deeper understanding of the molecular mechanism underlying the regulation of IL-24 gene expression is warranted for developing new anticancer drugs targeting IL-24 (Fig. 3). The drugs erlotinib (93-95) and ascorbic acid (Vc) (96) are special agonists for targeting IL-24. Erlotinib, as a small molecular epidermal growth factor receptor (EGFR) tyrosine kinase inhibitor, has been extensively investigated in the treatment of human lung cancer and other solid tumors (96, 97). Recently, the study has confirmed that Erlotinib

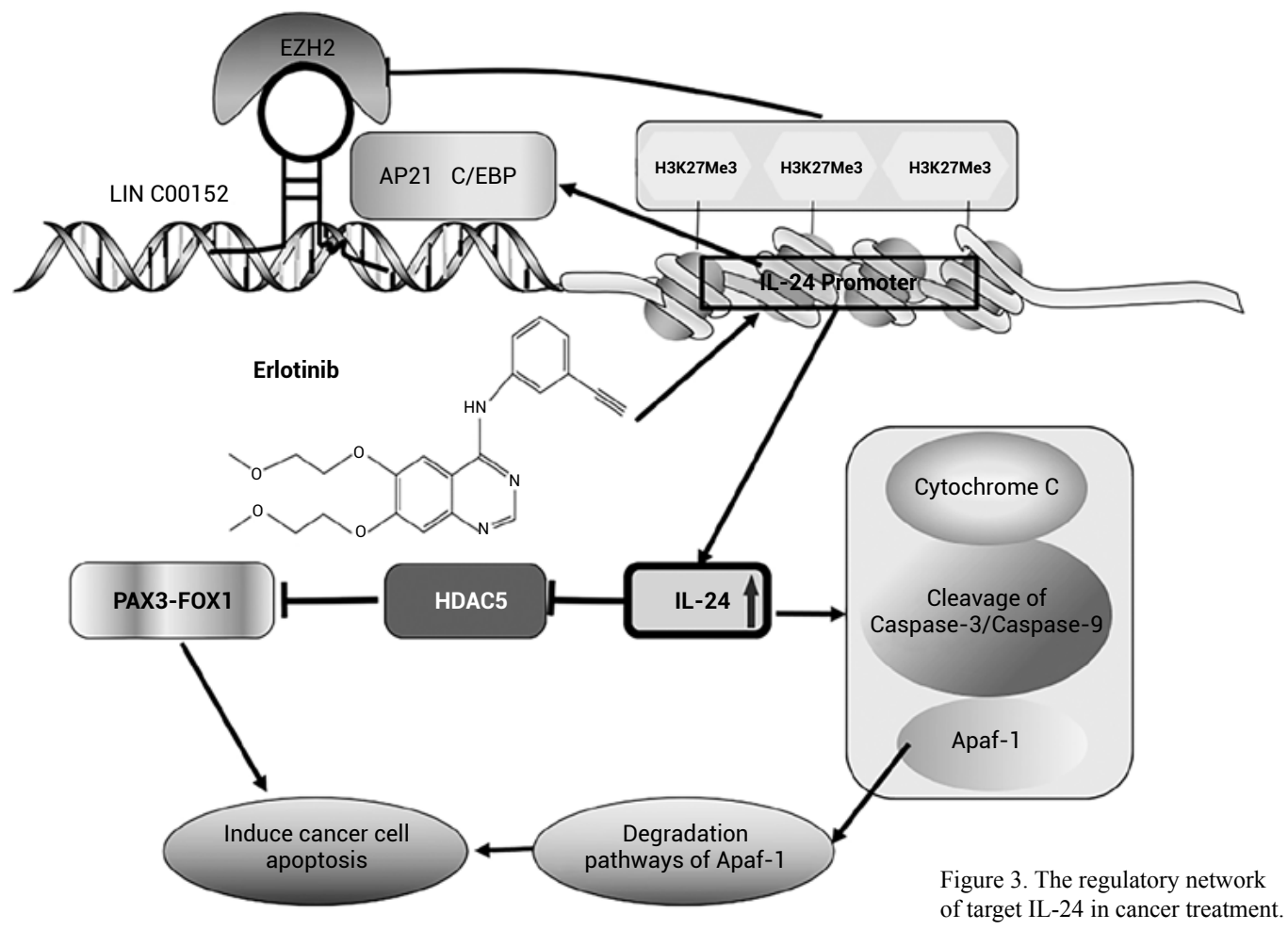


can significantly promote the expression of IL-24 by enhancing its promoter activity for improving cell growth inhibition and apoptosis induction in melanoma cells. Moreover, the enhancement of IL-24 promoter activity can inhibit the recruitment ability of LINC00152 to EZH2 to the IL-24 promoter region by regulating $\mathrm{H} 3 \mathrm{~K} 27 \mathrm{me} 3(98,99)$. In fact, LINC00152 has been considered as a key gene for gastric cancer and clear renal cell carcinoma and is involved in cell proliferation, apoptosis, migration, and invasion (100-101). Previously, studies have reported that long non-coding RNA PVT1 inhibited cell growth and induced apoptosis by binding to the enhancers of zeste homolog $2(\mathrm{EZH} 2)$ protein in LAD (a histone methyltransferase of the PRC2 complex) $(100,101)$. Recently, Madired et al. isolated the upstream region of IL-24 promoter region from a human placental genomic library, and identified GCG sequence as multiple AP21 and c-Jun/EBP (C/EBP) transcription factor recognition sites; moreover, ectopic expression of AP21/c-Jun or C/EBP significantly increased IL-24 promoter expression in melanoma cells (102). However, the c-Jun deletion mutant (TAM67) did not exhibit the ability to increase the IL-24 promoter activity (103). However, the c-Jun and $\mathrm{C} / \mathrm{EBP}$ family members $\beta 2 \mathrm{C} / \mathrm{EBP}$ are physiologically related transcription factors whose expression is positively associated with IL-24 mRNA expression. More recently, a study has demonstrated that the nuclear protein AP21 and C/EBP can bind to the promoter region of IL-24 for regulating the differentiation of melanoma cells by electrophoretic mobility shift assay. In addition, erlotinib-induced over-expression of IL-24 can regulate the expression of their upstream genes, including HDAC5 and PAX3-FOXO1. Indeed, HDAC5, as a PAX3-FOXO1 regulatory gene, plays a significant role in the suppression of muscle gene expression in RMS (Rhabdomyosarcoma) cells (103, 104). However, PAX3-FOXO1 does not directly bind to the IL-24 gene promoter, and the mediated regulation of IL-24 is HDAC5-dependent (105). Conversely, erlotinib-induced over-expression of IL-24 can promote the release of cytochrome-C, enhance the cleavage of caspase- 3 and caspase-9, and the expression of Apaf-1 protein, thereby inducing the activation of degradation pathways of Apaf-1, leading to cancer cell apoptosis.

Vitamin C (Vc), a potential candidate anticancer drug, has not yet been elucidated in combination with IL-24. However, the studies have shown that pharmacologic dose of Vc can enhance the anti-colon the cancer effect of IL-24-hBMMSCs (human bonederived marrow mesenchymal stem cells), suggesting that $\mathrm{Vc}$ can positively regulate the function and activity of IL-24 and facilitate the selection of cancer cells that have cancer stem-like cells. Moreover, an increasing number of studies have documented that combinatorial treatment of IL-24 with other therapeutic agents can induce selective enhancement of its antitumor effects as compared to its use alone, suggesting that combining IL-24 with other therapies may provide synergistic antitumor activities. Overall, these studies presented IL-24 as a promising candidate molecule that can selectively induce apoptosis in a wide array of cancer cells, both in vitro and in vivo, without affecting the normal cells. However, further in-depth studies are warranted to identify the molecular mechanism underlying the selective induction of apoptosis by IL-24 in cancer cells but not in normal cells.

\section{Prospect}

The present study implicated that IL-24 is a multi-functional enhancer of apoptosis selectively in cancer cells, although the molecular mechanism underlying this phenomenon remains to be completely elucidated. Furthermore, studies of the targeted anticancer drugs preliminary showed that the targeted induction of IL-24 expression could effectively provide the new selection for treatment in breast cancer; however, studies of novel drug molecules that can achieve specific treatment of more cancers with IL-24 as a new therapeutic target cancer in other cancers have not been reported. Using IL-24 as a potential specific target for developing the new anticancer drugs, our group is taking the screening from the natural products library to develop some novel anticancer candidates that can directly be combined with IL-24. Elucidating the molecular mechanism of these active compounds for promoting the expression of IL-24 and intervening in the function and related molecular processes in cells is of abundant significance for the treatment of cancer. Therefore, the discovery and development of anticancer drugs targeting novel treatment strategies utilizing IL-24 as a therapeutic target should be enhanced to determine the sensitivity and specificity of IL-24 over-expressed and silenced expression of IL-24 in cancer cells. Furthermore, studies elucidating the inhibitory effect of active compounds on the expression of IL-24 and identifying differential genes or protein expression in cancer cells are warranted to determine related pathways involved in the inhibition of the survival of cancer cells. This study presented IL-24 as a promising candidate cancer drug target and provided a theoretical basis for the development of IL-24 as a new biomarker agent for targeted cancer therapy and cancer gene therapy. 
In addition, the combination of IL-24 and chemotherapy can significantly enhance the antitumor effect, indicating that IL-24 has broad clinical application prospects.

\section{Acknowledgments}

This work was supported by the Natural Science Foundations of China (81760573 and 81430077), the Science and Technology Project of Guizhou Province (No.QKHLHZ[2016]7092, No.LH[2015]7345, No.QKHJC[2017]1069, No. QKHJC[2017]1412).

\section{Conflict of interest}

The authors report no conflicts of interest.

\section{REFERENCES}

1. Al-Lazikani B., Banerji U., Workman P.: Nat. Biotechnol. 30, 679 (2012).

2. Schirrmacher V.: Int. J. Oncol. 54, 407 (2019).

3. Redondo-Blanco S., Fernández J., Gutiérrez-delRío I., Villar C.J., Lombo F.: Front Pharmacol. 8, 109 (2017).

4. Nanayakkara A.K., Follit C.A., Chen G., Williams N.S., Vogel P.D., et al.: Sci. Rep. 8, 1 (2018).

5. Lee Y.T., Tan Y.J., Oon C.E.: Eur. J. Pharmacol. 834, 188 (2018).

6. Ke X., Shen L.: J. Neurosurg. 1, 69 (2017).

7. Lee H.M., Hwang K.A., Choi K.C.: Mol. Cell Endocrinol. 457, 103 (2017).

8. Damante M.A., Huntoon K., Olencki T., Thomas O.: Neurosurgery 66, 69 (2019).

9. Jan R., Chaudhry G.S.: Adv. Pharm. Bull. 9, 205 (2019).

10. Amaravadi R.K., Kimmelman A.C., Debnath J.: Cancer Discov. 9, 1167 (2019).

11. Carneiro B.A., El-Deiry W.S.: Nat. Rev. Clin. Oncol. 17, 1 (2020)

12. Croston G.E.: Expert. Opin. Drug Discov. 12, 427 (2017).

13. Miyahara R., Banerjee S., Kawano K., Efferson C., Tsuda N., et al.: Cancer Gene Ther. 13, 753 (2006).

14. Jiang H., Lin J.J., Su Z.Z., Goldstein N.I., Fisher P.B.: Oncogene 11, 2477 (1995).

15. Menezes M.E., Bhoopathi P., Pradhan A.K., Emdad L., Das S.K., et al.: Adv. Cancer Res. 138, 143 (2018).

16. Jamhiri I., Zahri S., Mehrabani D., Khodabandeh Z., Dianatpour M., et al.: Immunol. Invest. 1, 335 (2018).
17. Emdad L., Bhoopathi P., Talukdar S., Pradhan A.K., Sarkar D., et al.: Semin. Cancer Biol. 19, 30023 (2019).

18. Wang L., Vuletic I., Deng D., Crielaard W., Xie Z., et al.: Gene Ther. 24, 699 (2017).

19. Caudell E.G., John B.M., Nancy P., Suhendan E., Abner M.M., et al.: J. Immunol. 168, 6041 (2002).

20. Sarkar D., Su Z.Z., Lebedeva I.V., Sauane M., Gopalkrishnan R.V., et al.: Proc. Natl. Acad. Sci. U. S. A. 99, 10054 (2002).

21. Patani N., Douglas J.A., Mansel R., Jiang W., Mokbel K.: Cancer Cell Int. 10, 29 (2010).

22. Li Y.J., Song R., Korkola J.E., Archer M.C., Ben D.Y.: Oncogene 22, 3452 (2003).

23. Shaked Y., Bertolini F., Man S., Rogers M.S., Cervi D., et al.: Cancer Cell 7, 101 (2005).

24. Shaw A.R., Suzuki M.: Curr. Opin. Virol. 21, 9 (2016).

25. Hosseini E., Hosseini S.Y., Hashempour T., Fattahi M.R., Sadeghizadeh M.: Mol. Med. Rep. 15, 495 (2017).

26. Menezes M.E., Bhatia S., Bhoopathi P., Das S.K., Emdad L., et al.: Adv. Exp. Med. Biol. 818, 127 (2014).

27. Huang E.Y., Madireddi M.T., Gopalkrishnan R.V., Leszczyniecka M., Su Z., et al.: Oncogene 20, 7051 (2001).

28. Sarkar D., Su Z., Lebedeva I.V., Sauane M., Gopalkrishnan R.V., et al.: Biotechniques 33, 30 (2002).

29. Commins S., Steinke J.W., Borish L.: J. Allergy Clin. Immunol. 121, 1108 (2008).

30. Kotenko S.V.: Cytokine Growth Factor Rev. 13, 223 (2002).

31. Gupta P., Su Z.Z., Lebedeva 1.V., Sarkar D., Sauane M., et al.: Pharmacol. Ther. 111, 596 (2006).

32. Sauane M., Su Z.Z., Gupta P., Lebedeva I.V., Dent P., et al.: Proc. Natl. Acad. Sci. U. S. A. 105, 9763 (2008).

33. Robert S.: Cytokine Growth Factor Rev. 21, 315 (2010).

34. Alexander Z.: Cytokine Growth Factor Rev. 21, 325 (2010).

35. Logsdon N.J., Deshpande A., Harris B.D., Rajashankar K.R., Walter M.R.: Proc. Natl. Acad. Sci. U. S. A. 109, 12704 (2012).

36. Xu Y.K., Zhang F.J., Qin L., Miao J.C., Sheng W.H., et al.: Melanoma Res. 24, 20 (2014).

37. Lebedeva I.V., Su Z.Z., Chang Y., Kitada S., Reed J.C., et al.: Oncogene 21, 708 (2002).

38. Madireddi M.T., Dent P., Fisher P.B.: Oncogene 19, 1362 (2000). 
39. Julie A.E., Prieto V.G., Ekmekcioglu S., Broemeling L., Yekell S., et al.: J. Clin. Oncol. 15, 1069 (2002).

40. Hossein A.H., Swadesh K.D., Margaret A.P., Nichola C., Kellie A., et al.: Cancer Biol. Ther. 14, 1039 (2013).

41. Moira S., Lebedeva I.V., Su Z.Z., Choo H.T., Randolph A., et al.: Cancer Res. 64, 2988 (2004).

42. Madireddi M.T., Fisher P.B.: J. Cell Physiol. 185, 36 (2000).

43. Ekmekcioglu S., Ellerhorst J., Mhashilkar A.M., Sahin A.A., Read C.M., et al.: Int. J. Cancer 94, 54 (2010).

44. Saeki T., Mhashikar A., Swanson X., Yang X.H., Sieger K., et al.: Oncogene 21, 4558 (2002).

45. Chada S., Sutton R.B., Ekmekcioglu S., Ellerhorst J., Mumm J.B., et al.: Int. Immunopharmacol. 4, 649 (2004).

46. Frewer N.C., Ye L., Sun P.H., Owen S., Ji K., et al.: Int. J. Mol. Med. 31, 1097 (2013).

47. Shinichiro K., Takashi N., Anupama M., Jack A.R., Sunil C., et al.: Mol. Ther. 6, 637 (2015).

48. Wang M., Tan Z., Thomas E.K., Liang P.: Genes Immun. 5, 363 (2004).

49. Ma G., Kawamura K., Shan Y., Okamoto S., Li Q., et al.: Cancer Gene Ther. 21, 31 (2014).

50. Leath C.A., Kataram M., Bhagavatula P., Gopalkrishnan R.V., Dent P., et al.: Gynecol. Oncol. 94, 352 (2004).

51. Pradhan A.K., Bhoopathi P., Talukdar S., Shen X.N., et al.: Mol. Cancer Ther 17, 1951 (2018).

52. Hingorani S.R., Petricoin E.F., Maitra A., Rajapakse V., King C., et al.: Cancer Cell 4, 437 (2003).

53. Sainz-Perez A., Gary-Gouy H., Gaudin F., Maarof G., Marfaing-Koka A., et al.: J. Immunol 181, 6051 (2008).

54. Zhang Y., Liu Y., Xu Y.: Front. Oncol. 9, 1401 (2019).

55. Deng L., Yang X., Fan J., Ding Y., Peng Y., et al.: Oncol. Res. 28, 579 (2021).

56. Sauane M., Su Z.Z., Dash R., Liu X., Norris J.S., et al.: J. Cell Physiol. 222, 546 (2010).

57. Fisher P.B., Gopalkrishnan R.V., Chada S., Ramesh R., Grimm E.A., et al.: Cancer Biol. Ther. 2, 22 (2003).

58. Sauane M., Gopalkrishnan R.V., Sarkar D., Su Z.Z., Lebedeva I.V., et al.: Cytokine Growth Factor Rev. 14, 35 (2003).

59. Saeki T., Mhashilkar A., Chada S., Branch C., Roth J.A., et al.: Gene Ther. 7, 2051 (2000).

60. Hanahan D., Weinberg R.A.: Cell 144, 646 (2011).

61. Gopalkrishnan R.V., Sauane M., Fisher P.B.: Int. Immunopharmacol. 4, 635 (2004).
62. Cunningham C.C., Chada S., Merritt J.A., Tong A., Senzer N., et al.: Mol. Ther. 11, 149 (2005).

63. Morris R., Kershaw N.J., Babon J.J.: Protein Sci. 27, 1984 (2018).

64. Hu C.W., Yin G.F., Wang X.R., Ren B.W., Zhang W.G., et al.: Oncol. Res. 22, 159 (2015).

65. Chakrabarti A., Sadler A.J., Kar N., Young H.A., Silverman R.H., et al.: J. Biol. Chem. 283, 25132 (2008).

66. Jia J., Li S., Gong W., Ding J., Fang C., et al.: Oncol. Rep. 25, 195 (2011).

67. Lebedeva I.V., Su Z.Z., Sarkar D., Kitada S., Dent P., et al.: Cancer Res. 63, 8138 (2003).

68. Zhang K.J., Wang Y.G., Cao X., Zhong S.Y., Wei R.C., et al.: Hum. Gene Ther. 20, 818 (2009).

69. Wang M., Liang P.: Immunol. 114, 166 (2010).

70. Dumoutier L., Leemans C., Lejeune D., Lotenko S.V., Renauld J.C.: J. Immunol. 167, 3545 (2001).

71. Dumoutier L., Lejeune D., Hor S., Fickenscher H., Renauld J.C.: Biochem. J. 370, 391 (2003).

72. Ramesh R., Ito I., Gopalan B., Saito Y., Mhashilkar A.M., et al.: Mol. Ther. 9, 510 (2004).

73. Dash R., Bhutia S.K., Azab B., Su Z.Z., Quinn B.A., et al.: Cytokine Growth Factor Rev. 21, 381 (2010).

74. Zheng M., Bocangel D., Doneske B., Mhashilkar A., Ramesh R., et al.: Cancer Immunol. Immunother. 56, 205 (2007).

75. Li Y.J., Liu G., Li Y.M., Vecchiarelli-Federico L.M., Liu J.C., et al.: Mol. Cancer Res. 11, 593 (2013).

76. Li Y.J., Liu G., Xia L., Xiao X., Liu J.C., et al.: Oncotarget 6, 36943 (2015).

77. Hong S., Laimins L.A.: Virus Res. 231, 34 (2017).

78. Luni E., Lebedeva I.V., Su Z.Z., Gupta P., Sarkar D., et al.: J. Cell Physiol. 210, 549 (2010).

79. Ma M., Zhao L., Sun G., Zhang C., Liu L., et al.: Oncol. Rep. 35, 3122 (2016).

80. Lebedeva I.V., Washington I., Sarkar D., Clark J.A., Fine R.L., et al.: Proc. Natl. Acad. Sci. U. S. A. 104, 3484 (2007).

81. Tian H., Zhang D., Gao Z., Li H., Zhang B., et al.: Cancer Gene Ther. 21, 416 (2014).

82. Kawabe S., Nishikawa T., Munshi A., Roth J.A., Chada S., et al.: Mol. Ther. 6, 637 (2002).

83. Mhashilkar A.M., Stewart A.L., Sieger K., Yang H.Y., Khimani A.H., et al.: Mol. Ther. 8, 207 (2003).

84. Bhoopathi P., Lee N., Pradhan A.K., Shen X.N., Das S.K, et al.: Cancer Res., 76, 3572 (2016).

85. Pradhan A.K., Talukdar S., Bhoopathi P., Shen X.N., Emdad L., et al.: Cancer Res. 77, 949 (2017). 
86. Park M.A., Yacoub A., Sarkar D., Emdad L., Rahmani M., et al.: Autophagy 4, 513 (2008).

87. Bhutia S.K., Dash R., Das S.K., Azab B., Su Z.Z., et al.: Cancer Res. 70, 3667 (2010).

88. Park M.A., Walker T., Martin A.P., Allegood J., Vozhilla N., et al.: Mol. Cancer Ther. 8, 1280 (2009).

89. Yacoub A., Gupta P., Park M.A., Rhamani M., Hamed H., et al.: Mol. Cancer Ther. 7, 314(2008).

90. Yacoub A., Park M.A., Gupta P., Rahmani M., Zhang G., et al.: Mol. Cancer Ther. 7, 297 (2008)

91. Shi H., Wei L.L., Yuan C.F., Yang J.X., Yi F.P., et al.: Saudi Med. J. 28, 1671 (2007).

92. Huo W., Li Z.M., Zhu X.M., Bao Y.M., An L.J. Oncol. Rep. 30, 986 (2013).

93. Deng W.G., Kwon J., Ekmekcioglu S., Poindexter N.J., Grimm E.A.: Melanoma Res. 21, 44 (2011).

94. Berndsen R.H., Swier N., Beijnum J.R., Sliwinska P.N.: Cancers 11, 1878 (2019).

95. Panneerselvam J., Srivastava A., Mehta M., Chen A., Zhao Y.D., et al.: Cancers 11, 1879 (2019).
96. Wickersham K.E., Hodges T.K., Edelman M.J., Song Y., Nan M., et al.: Nurs. Res. 68, 110 (2019).

97. Zhao J., Liu Y., Zhang W., Zhou Z., Wu J., et al.: Cell Cycle 14, 3112 (2015).

98. Chen W.M., Huang M.D., Sun D.P., Kong R., Xu T.P., et al.: Oncotarget 7, 9773 (2016).

99. Wu Y., Tan C., Weng W.W., Deng Y., Zhang Q.Y., et al.: Am. J. Cancer Res. 7, 285 (2016).

100. Wan L., Sun M., Liu G.J., Wei C.C., Zhang E.B., et al.: Mol. Cancer Ther. 15, 1082 (2016).

101. Chen Q.N., Chen X., Chen Z.Y., Nie F.Q., Wei C.C., et al.: Mol. Cancer Ther. 13, 17 (2017).

102.Pan L., Pan H., Jiang H., Du J., Wang X.L., et al.: Cell Mol. Immunol. 7, 221 (2010).

103. Imaeda H., Nishida A., Inatomi O., Fujiyama Y., Andoh A.: Int. J. Mol. Med. 28, 993 (2011).

104.Zhang M., Zhu B., Davie J.: J. Biol. Chem. 290, 310 (2015).

105. Lacey A., Hedrick E., Cheng Y., Mohankumar K., Warren M., et al.: Mol. Cancer Ther. 17, 2756 (2018). 